\title{
Emergency remote teaching during the COVID-19 pandemic: Parents experiences and perspectives
}

\author{
Ozge Misirli $^{1}$ (D) Funda Ergulec ${ }^{1}$ (D)
}

Received: 29 December 2020 / Accepted: 22 March 2021 / Published online: 29 March 2021

(C) The Author(s), under exclusive licence to Springer Science+Business Media, LLC, part of Springer Nature 2021

\begin{abstract}
The coronavirus disease 2019 (COVID-19) pandemic caused an emergency transform from traditional to distance learning at all levels of education, which is called emergency remote teaching. To explore parents' views on students' experiences of remote teaching during the COVID-19 pandemic, and their experience and perspectives toward remote teaching during the lockdown of the COVID-19 pandemic, a questionnaire was developed and distributed to parents who have at least one child who had attended a face-to-face learning environment prior to school closures and started remote teaching during the pandemic. 983 parents participated in the study. The parents' views on students' experiences of remote teaching during the COVID19 pandemic, their experiences and perspectives toward remote teaching were discussed. The results suggested that the remote teaching process has been challenging for both students and parents. It is found that the remote teaching practices were mainly covered in core courses; remote teaching is considered as unsuitable for young children and students with special needs; the parents complain about social isolation, lack of interactivity, and increased screen time; and remote teaching has placed a heavy burden on parents. Lastly, the parents stated that their children acquired self-regulated learning skills and digital socialization during emergency remote teaching.
\end{abstract}

Keywords Emergency remote teaching $\cdot$ COVID-19 pandemic $\cdot$ Parents experiences and perspectives $\cdot$ Distance learning

Funda Ergulec

fundaergulec@gmail.com

Ozge Misirli

ozgeekarakus@gmail.com

1 Eskisehir Osmangazi University, Eskisehir, Turkey 


\section{Introduction}

The coronavirus disease 2019 (COVID-19) pandemic caused nationwide school closures in several countries which affected hundreds of millions of students. In response to the COVID-19 outbreak, the school closures in Turkey began in midMarch 2020 (16 March) and continued for the rest of the school year for 2020. While the disease does not cause severe illness in children, they have an important role in transmission of the virus (European Centre for Disease Prevention \& Control, 2020). Thus, school closures were considered as a crucial step to reduce the transmission of COVID-19 (Abdulamir \& Hafidh, 2020). Unexpected school closures influenced the education of students and their families, as well as the teachers.

With the school closures, classes at all levels moved from traditional to distance-learning environments. Schools and teachers have made efforts to design and deliver online courses through the Internet or TV broadcasts. Approximately 200 country-wide school closures due to COVID-19 affected more than 1.5 billion learners of all ages (UNESCO, 2020; UNICEF, 2020). Approximately 25 million learners were affected by the country-wide closures in Turkey. In a situation where education is being delivered completely online, the teaching and learning environment and educational interactions has changed including knowledge construction and socialization.

In a normal situation, online education creates flexibility for learning and teaching from anytime and anywhere. However, the COVID-19 pandemic prompted an emergency transition from traditional to distance learning at all levels of education, called emergency remote teaching (Hodges et al., 2020). Emergency remote teaching was formed in response to the pandemic. The situation was different from the well-planned traditional method to online learning as it was unexpected and unprecedented for teachers, students, and parents. For the first time in world history, all students were required to take all their classes online and all teachers were required to teach online. However, well-planned online learning is a complex process where careful instructional design and development is needed to create an effective learning environment (Ergulec, 2019; Palloff \& Pratt, 2013). Emergency remote teaching is a temporary teaching solution to an emergent problem. "The primary objective in these circumstances is not to re-create a robust educational ecosystem but rather to provide temporary access to instruction and instructional supports in a manner that is quick to set up and is reliably available during an emergency or crisis" (Hodges et al., 2020, p. 6). Thus, the courses that are delivered in this kind of situation should not be considered as long-term solutions. A distinction should be made between these two terms as "the degree to which educators believe in distance education these days will play a significant role in the prosperity of distance education in a post-COVID world" (Bozkurt \& Sharma, 2020, ii). In addition, emergency remote teaching in this particular situation created an obligation for students, while wellplanned distance learning creates a flexible and alternative learning environment (Bozkurt \& Sharma, 2020).

Shifting from the concept of online learning to emergency remote teaching has brought new challenges and opportunities at a social and technological level, 
which influenced the physical and mental health of children. According to the theory of social constructivism, learning occurs in a social context with individuals' interactions by active participation, scaffolding, and knowledge exchange (Vygotsky, 1978). While the school and classroom environments are important places for students to have social experiences, children's homes have become the new educational setting without physical social interactions with their teachers and peers. Social isolation and lack of interactivity have been considered as a major shortcoming of emergency remote teaching, as technology became the children's only channel to interact with teachers and peers (Dong et al., 2020).

Connections with social isolation and lack of interaction are likely to have detrimental effects on children's physical and mental health during the spread of the virus (Brazendale et al., 2017). The negative effects include psychological impacts such as longer durations of quarantine, fears of infection, frustration and boredom, inadequate supplies, inadequate information, financial loss, and stigma (Brooks et al., 2020). In addition to those negative psychological effects, the school closures and being apart from school, peers and teachers influence the health of children. This includes a lack of interaction with peers, friends, classmates, and teachers (Brazendale et al., 2017). In this respect, schools at all levels have a critical role, "not only in delivering educational materials to children, but in offering an opportunity for students to interact with teachers and obtain psychological counselling" (Wang et al., 2020, p. 395).

In addition to the social level challenges, parents and children were influenced at technological levels as well. Parents and students who are accustomed to faceto-face education, who do not have technological equipment, knowledge and skills have difficulty in following lessons conducted in distance education (Telli Yamamoto \& Altun, 2020). In virtual learning environments, parent support has significant contributions for student learning (Feng \& Cavanaugh, 2011; Lee \& Figueroa, 2012). Challenges that impact parent involvement in virtual learning environments include lack of technology access (Hollingworth et al., 2011), low self-efficacy toward technology (Povey et al., 2016) and lack of interest for technology use (Beckman et al., 2019). While the literature suggests that parent involvement is an important factor for student learning, the studies concerning parent involvement in children's learning focus mainly on the traditional school settings (Liu et al., 2010). Considering the lack of physical presence of teachers and the time spent by students with their parents during virtual learning, parent participation in the learning process is especially important for student achievement (Liu et al., 2010).

During the emergency remote teaching, parents can be considered as one of the most important stakeholders of distance education, as they are the only ones who physically accompany their children. Since children's homes became the new learning environment during the pandemic, parents influence their children's learning by providing digital technologies, learning environment, and learning how to support their children. This new situation placed a heavy burden on caregivers and parents (Chang \& Satako, 2020; Dong et al., 2020; Garbe et al., 2020; Pew Research Center, 2020). While little research has been conducted to understand parents' views during this kind of learning experience, parents' 
perspectives and experiences of emergency remote teaching can influence the quality and quantity of online learning in the future. The studies conducted to understand parents' beliefs, attitudes, and experiences during the COVID-19 pandemic (e.g., Dong et al., 2020; Garbe et al., 2020; Parczewska, 2020; TrzcińskaKról, 2020) belong to certain grade levels and are conducted in certain countries; such as China, United States, and Poland. To fill this research gap, this particular study has reached a very large group of parents whose children attend various grade levels in Turkey.

When the COVID-19 pandemic is over, the education system should not forget about the experiences we gain during the emergency remote teaching. Similar circumstances (disaster) are likely to arise in the future and school closures would then be expected to implement the emergency remote teaching. Thus, it is important now to evaluate our experiences to be better prepared for future needs to carry out the emergency remote teaching (Hodges et al., 2020). In such an emergent situation, the system usually does not consider the feelings of students and parents. However, all these emergency changes in the education system have caused parents to be concerned about their children's education, physical and mental health (Brooks et al., 2020). As voiced by Bozkurt and Sharma (2020), when things go back to normal, the students will remember how they felt during this situation, as well as their parents. Given the possibility of encountering similar situations in the future, parents' views are important to guide and contribute to the process.

\subsection{The purpose of the study}

Emergency remote teaching requires circumstances different from usual conditions since we had not been prepared in terms of technical infrastructure, professional development, and skill set. Lack of preparation by the schools, students and their parents' is the main difficulty in distance education carried out during the pandemic. Interruption of the education in schools made the rapid transition to distance education more important. It has brought along several problems for parents, such as lack of infrastructure and skills related to the education of their children. In this emergent situation, the majority of students needed the guidance of their parents. Given the possibility of encountering similar situations in the future, parents' views are important in order to guide and contribute to the process. Since all these are taken into consideration, the aim of the study was first to understand the current emergency remote teaching situation in Turkey and experiences of students with the remote teaching during the COVID-19 pandemic. In this aspect, the content of children's online learning and their interactions with the remote teaching were investigated. The aim was also to reveal the perspectives of the parents during emergency remote teaching carried out due to the pandemic period. Parents' perspectives toward remote teaching, including feelings, issues, struggles, and satisfactions they have encountered during the emergency remote teaching, and their presence during the emergency remote teaching were investigated. The study provides an analysis of the 
status of online learning at home during the pandemic, what parents did, how were they involved, and how they felt during this time. For this purpose, the following research questions have been explored:

- What are the parents' views on students' experiences of remote teaching during the COVID-19 pandemic?

- What are the parents' experiences of remote teaching during the COVID-19 pandemic?

- What are the parents' perspectives toward remote teaching during the COVID-19 pandemic?

\section{Method}

Following the announcement of the pandemic, as of 16 March, face-to-face education was interrupted in schools in Turkey and it was decided that all educational institutions should continue with distance education. With the school closures, education in Turkey had to be continued via alternative platforms. The Ministry of National Education (MoNE) in Turkey has decided to use online platform-EBA (Educational Informatics Network) and national television channel-TRT (Turkish Radio and Television Corporation) to perform the remote teaching. EBA was used as the main platform for the remote teaching. It is a digital educational portal which was developed by MoNE during the 2011-2012 academic year. The portal includes educational materials such as books, videos, and several activities to support students' learning and includes a synchronous platform for video and audio conferencing. Both synchronous and asynchronous teaching methods can be used in the portal. MoNE collaborated with the leading GSM operators and the operators provided $8 \mathrm{~GB}$ of free Internet access to the students. TRT, the national television channel, was used by students who did not have smartphones or Internet access at home.

In EBA portal, students were able to access courses which are divided by grade levels. The courses of primary schools were offered to students from 9:00am to 2:00 pm, and replays of courses were performed from 2:30 pm to 7:30 pm. The courses of middle schools were offered to students from 9:00am to 4:00 pm and replays of courses were performed from $4.30 \mathrm{pm}$ to $11.30 \mathrm{pm}$. Furthermore, for students in the eighth and twelve grades who were preparing for the high-stake examinations, live courses were offered by their own teachers at school. Private schools have also implemented their own solutions in the process. Many private schools supported students with live lessons regardless of class levels.

\subsection{Design}

The studies aim is to examine the parents' views on students' experiences of remote teaching during the COVID-19 pandemic, and their experiences and perspectives 
towards remote teaching during the lockdown. Parents' qualitative and quantitative data were collected for this purpose. Concurrent compilation of qualitative and quantitative results was gathered simultaneously. Qualitative data was used to support and expand on quantitative data. The study's method section includes the design, participants, instruments, data collection process, and data analysis.

\subsection{Participants}

The experiences of students during the remote teaching and their parents' experience and perspectives toward the remote teaching during the lockdown of the COVID19 pandemic, were explored using a questionnaire. A combination of convenience sampling (researchers themselves contacted parents to invite them to participate in the study) and snowball sampling (the participating parents were asked to forward the questionnaire to their child's school via social media or WhatsApp groups) were used. The aim was to ensure maximal participation. As a result, the questionnaire was sent out via online platforms and filled out voluntarily by 982 parents whose children attend a public or private school during the 2019-2020 school year. Out of 982 parents who filled out the questionnaire, 445 had children in primary school and 275 had children in middle school. 187 of these parents had children in pre-school and 76 had children in high school. Considering the distribution of parents according to their children's school level, the parents who had children in primary and secondary school had the highest rate in the research sample.

\subsection{Instruments}

A questionnaire developed by the researchers was used to explore the opinions of the Turkish parents during the emergency remote teaching carried out due to the pandemic. The items in the questionnaire were developed based on experiences of the researchers and a review of the literature (e.g., Dong et al., 2020; Lase et al., 2020). It is worth mentioning the experiences of researchers here, they both work as faculty members at the faculty of education, teach during the pandemic, and are interested in teacher development and training in distance education. In addition, they both have children who attend school during the pandemic.

During the item development for the questionnaire, opinions of one psychological counselor and four colleagues from the Faculty of Education were received. These four colleagues work in the Departments of Language and Literacy Education, Educational Sciences, Pre-School Education, and Special Education, respectively. After the revisions, the questionnaire was formed into the final version. The questionnaire consists of 23 questions, two of which are open-ended. The questionnaire included questions designed to solicit parent input on the emergency remote teaching implemented during the pandemic period. Two open-ended questions were asked regarding anything they would like to change while their children were being educated remotely during the COVID-19 pandemic and their favorite approach of their children's school during the COVID-19 remote teaching process. 


\subsection{Data collection procedure}

The questionnaire was delivered to the parents through online platforms and took approximately 5 to $10 \mathrm{~min}$ to respond. Due to the pandemic, the data collection process could not be conducted face-to-face, thus the participants were reached through online platforms such as social media and messaging applications. It is worth noting that the greatest bias in our sample was caused by the online administration of the questionnaire, as parents who have Internet connections took part in the study. The process began with the distribution of the data collection tool to parents who had at least one child who attended a face-to-face learning environment prior to school closures due to the pandemic and who began remote teaching during the pandemic. Then the participating parents were asked to forward the questionnaire to their child's school social media or WhatsApp groups.

\subsection{Data analysis}

Descriptive statistics were used to analyze the quantitative data. After interpreting the percentage distribution of the responses to the questionnaire, graphics and tables were used to make it more understandable. The qualitative data were analyzed using the content analysis method. The purpose of using content analysis was to organize and extract meaning from the data collected and to draw realistic conclusions (Berg, 2009; Şimşek \& Yıldırım, 2011). Thematic coding was used for the qualitative question. In this way, themes and sub-themes were determined. The data collected from the open-ended questions were coded by two researchers and then similar ideas were recombined with the thematic coding approach. In the interpretation of qualitative data, participants' quantitative responses were included, and it was aimed to establish a link between quantitative and qualitative data. In this way, the data was analyzed with a more holistic perspective.

In an effort to address methodological issues in this study, trustworthiness and transferability of the study were considered. Qualitative researchers seek to develop trustworthiness, which is considered as the primary criterion for establishing the validity (Lincoln \& Guba, 1985). In this study, several approaches to establish trustworthiness were established. The role of researchers in the process, the process of developing data collection tools, data collection, and analysis procedures were explained in detail in order to ensure trustworthiness of the research. The data collection tool was developed based on experiences of the researchers and a review of the literature; then expert opinions were received from colleagues in different fields. Triangulation techniques (Lincoln \& Guba, 1985) were implemented by collecting data using multiple methods of quantitative and qualitative approaches (including multiple-choice and open-ended questions). Tables and graphics were used to increase the comprehensibility of the quantitative data. The analysis of open-ended questions was used to support quantitative data. Lastly, the findings were supported by direct quotations by the participants. To enhance transferability of the study, detailed description is provided (Yin, 2009), peer debriefing and negative case analysis were used (Lincoln \& Guba, 1985). 
Table 1 Students' school type, level, and internet access

\begin{tabular}{|c|c|c|c|c|c|c|c|}
\hline \multicolumn{2}{|c|}{ School Type } & \multicolumn{4}{|c|}{ School Level } & \multicolumn{2}{|c|}{ Internet Access } \\
\hline Public & Private & Pre- school & Primary school & Middle school & High school & Sufficient & Insufficient \\
\hline $51 \%$ & $49 \%$ & $19 \%$ & $45 \%$ & $28 \%$ & $8 \%$ & $95 \%$ & $5 \%$ \\
\hline
\end{tabular}

\section{Findings}

The table regarding the school type, school level, and Internet access of the children of the parents participating in the study is given below (Table 1).

The distribution of the children of the parents participating in the study by school type is examined and it is observed that the rate of those who attend public school and private school is about the same. In addition, the children attending primary school have the highest rate in the research sample. The vast majority of the participants stated that they have sufficient Internet access. The problems experienced by the participants who stated that they had insufficient Internet access were also discussed.

\subsection{Students' remote teaching experiences during the COVID-19 pandemic}

During the remote teaching, parents and children mostly used technological devices such as personal laptops, desktop computers, and tablets (81.6\%) to access distance education lessons. $40 \%$ of those participating in distance education stated that they used mobile devices during the process, and $33.4 \%$ stated that they used TV broadcasts to access lessons and educational materials.

The courses that were offered by schools during the remote teaching are shown in Fig. 1. As the figure shows, in all school levels, except pre-school, schools have given priority to courses like Mathematics, Literacy, Social Studies, and Science Education. Other courses like Art, Music, and Physical Education were kept in

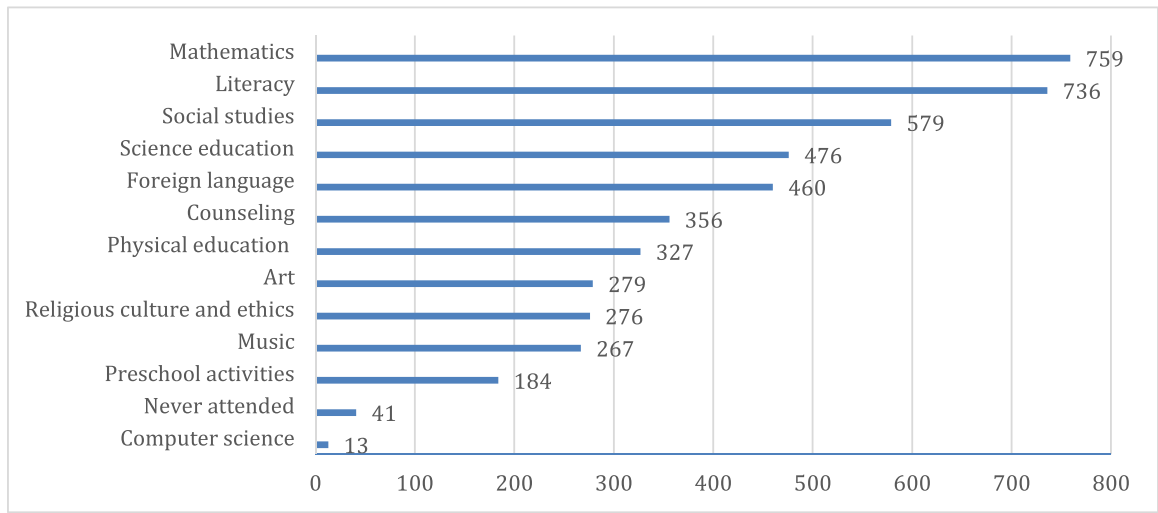

Fig. 1 The courses that are offered by schools during the remote teaching 
Fig. 2 Attendance to the remote teaching

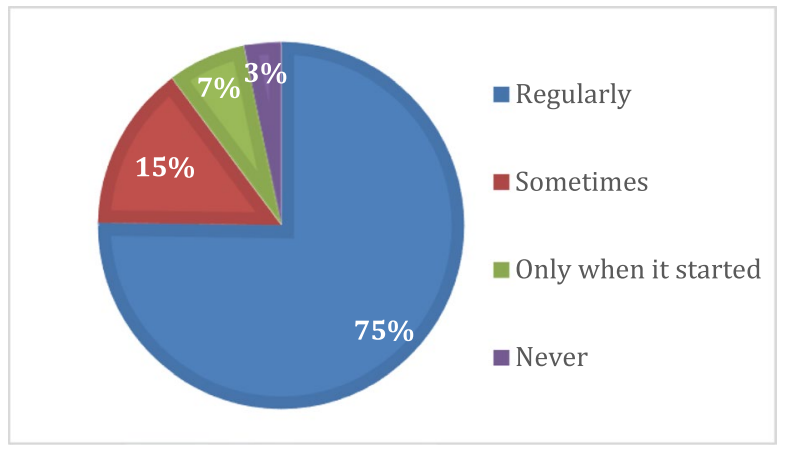

low priority (Fig. 1). Some of the parents expressed their opinions about the lack of course variety. "Courses such as music or physical education should also be included in distance education. Delivering only core courses improves my child in one way, which is academically, not socially." "Sports and music courses were lacking in distance education; these types of activities should be added for creative and kinesthetic children."

$76 \%$ of the parents participating in the study stated that they regularly attended the live lessons conducted by their schools and EBA lessons by the Ministry of National Education. 15\% stated that they attended distance education occasionally. While some parents stated that they participated at the beginning of the distance education then dropped out (7\%), $2 \%$ of the participants stated that they had never attended the distance education (Fig. 2).

The remote teaching has been delivered via several different platforms (Fig. 3). $64.8 \%$ of the parents stated that their children attended the live lessons during the remote teaching. In addition to the live lessons, the parents stated that they followed the activities broadcasted by EBA, both on TV broadcast and Internet. In addition to the listed platforms, educational communication was continued through phone and school's private learning management systems (LMS).

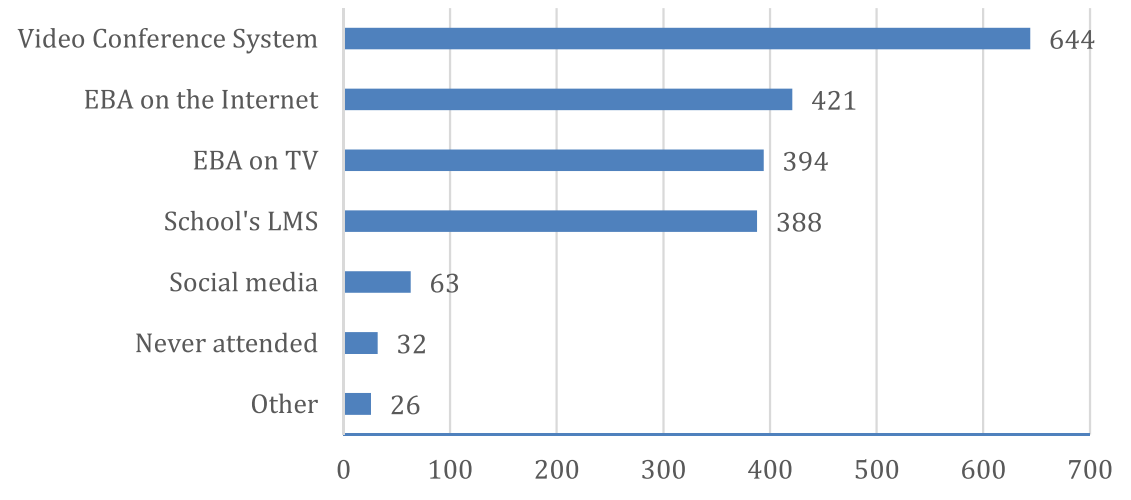

Fig. 3 The platforms that used to attend the remote teaching 
Communication with the teacher

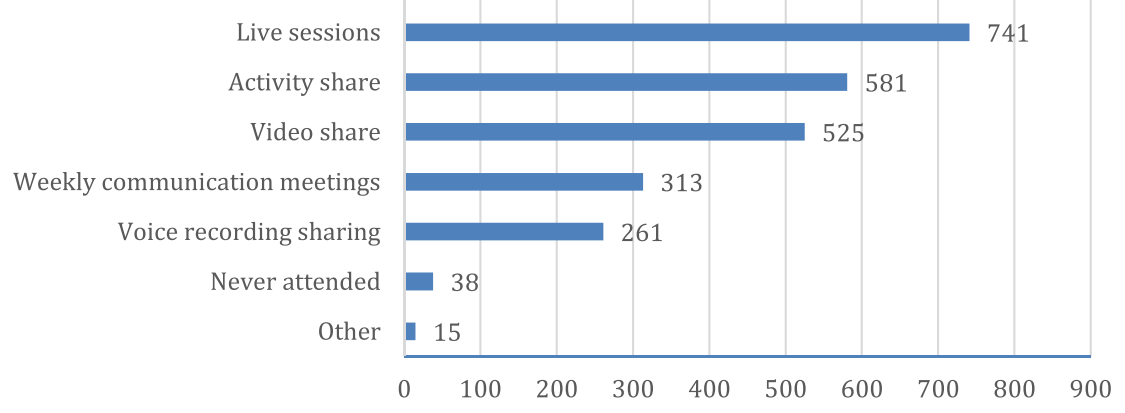

Fig. 4 The activities carried out by schools during the remote teaching

Parents stated that the remote teaching process was generally structured as teaching live lessons (75\% of the participants) and meetings with teachers for the aim of staying in touch ( $85 \%$ of the participants). In addition to those, activity, video, or audio sharing and weekly communication meetings were carried out by schools (Fig. 4).

\subsection{Parents' experiences of remote teaching during the COVID-19 pandemic}

Although a certain age group can carry out distance education with their own skills, some age-groups needed parental support. The chart below shows how parents were involved in the remote teaching process (Fig. 5).

Approximately half of the participants provided technical support to their children and then left them alone during the live class sessions. 34\% of the parents either stood by their children during the live sessions or actively participated in the remote teaching (Fig. 5). In detail, the data showed that the parents of young children (preschool and primary school level) were involved in the process not only providing technical support but also participating. The parents who stated that they stood by their children during the course were mostly the parents of preschool children $(54.5 \%)$ and primary school children (36.2\%). This rate is lower for participants with children attending middle and high school. $14.7 \%$ of the participants who had a

Fig. 5 Parents' presence during the remote teaching

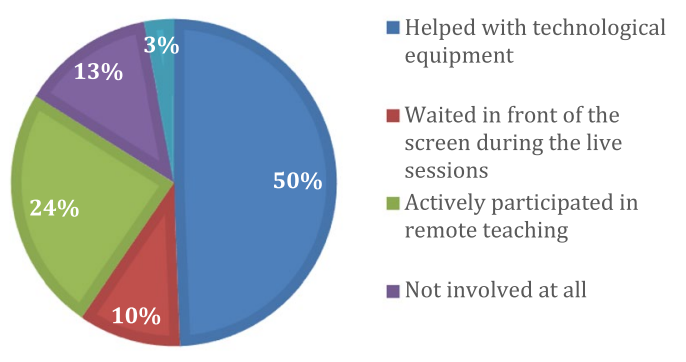


child going to high school and $23.3 \%$ of the parents who had a child going to middle school stated that they actively participated in the remote teaching process.

In addition, $48 \%$ of parents of high school children and $23.7 \%$ of parents of middle school children stated that they did not support their children in the process. On the other hand, $3.7 \%$ of the parents with a child attending pre-school and $4.8 \%$ of the participants of primary school children stated that they did not need to provide support for their children. Considering the ratio of all participants, $13.3 \%$ of the participants reported that their children engaged in the process without any assistance. Thus, it can be concluded that the need for assistance in addition to technical support in distance education is related to students' age level and their skills due to their age.

\subsection{Parents' perspectives toward the remote teaching during the COVID-19 pandemic}

About half of the parents (48.8\%) stated that they found their school sufficient during the remote teaching process. In addition, there are parents (15.1\%) who found their school as very sufficient during the remote teaching process and parents $(24.5 \%)$ who found their school not sufficient at all.

With the COVID-19 pandemic, children had to become socially disconnected from their peers and teachers. Supporting social and emotional needs of children during this situation became important. According to the study results, it was found that some of the schools took this into account and supported their students' social and emotional needs during the pandemic. While $53.6 \%$ of the parents who participated in the study stated that their children's social needs were partially met, $21.9 \%$ of them stated that their schools were insufficient in meeting the social needs of their children.

Self-regulation in an online class can be considered as one of the pre-requisites. While $57 \%$ of the participants stated that the remote teaching process partially contributed to their children's self-regulated learning, $21.6 \%$ of them stated that it had no influence in this respect. With the COVID-19 lockdown, the social life of students had been interrupted, parents stated that digital socialization is the most basic skill that their children acquired in this process (Fig. 6). Some of the parents also stated that the children had fun during the remote teaching process, and it supported learning. In addition, some parents stated that the process did not help their children to acquire any skills, and even regressed existing skills.

Parents who participated in the study were also asked about their opinions related to screen time in this process. $76.9 \%$ of the parents stated that their children have spent more time in front of the screen compared to lives before the pandemic. $25.6 \%$ of the parents stated that they did not take any precautions regarding the screen time and $6.2 \%$ stated that they only allowed screen time during distance learning. $69 \%$ of the parents stated that they regulated their children' screen time outside the online lessons.

According to the parents, the biggest challenge experienced during the remote teaching process was the increase in the time spent in front of the screen (71.7\%) (Fig. 7). In addition, parents stated that during the remote teaching the 


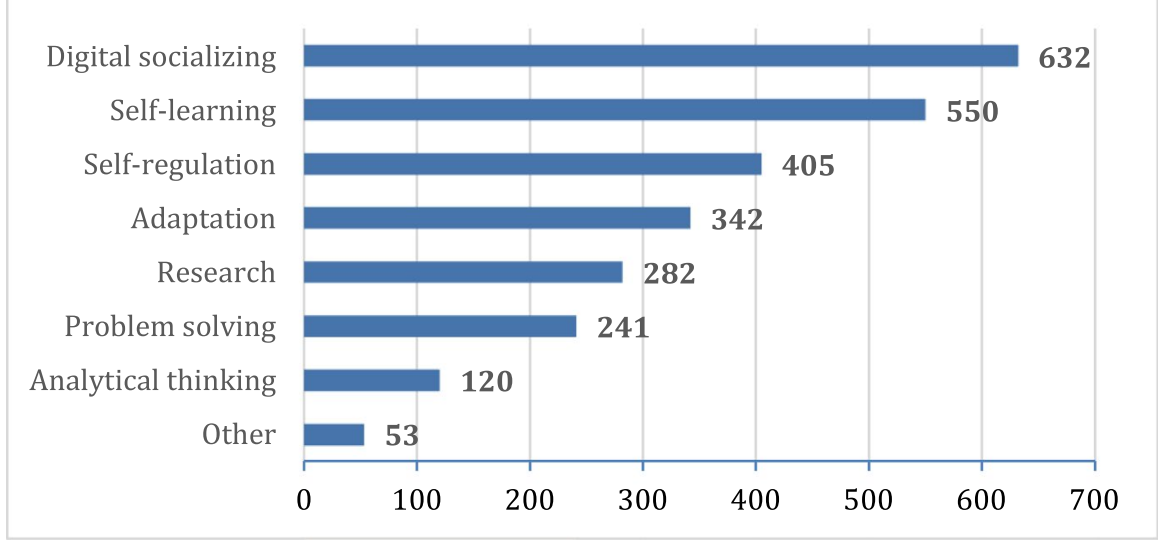

Fig. 6 Children's abilities and the remote teaching

children could not communicate well with their peers and teachers, they were reluctant toward learning, there was lack of technological infrastructure, the school activities disrupted their day, there was communication breakdown with their children, the children surfed on the Internet while in class, they had concerns regarding the platform that the lessons were held, they had insufficient technological skills. Parents also stated that their workload increased, their children got bored, and had problems with discipline and concentration.

The answers given to the open-ended question that asked if there were anything that parents want to change about the COVID-19 remote teaching process are categorized under themes: infrastructure issues, communication/interaction problems,

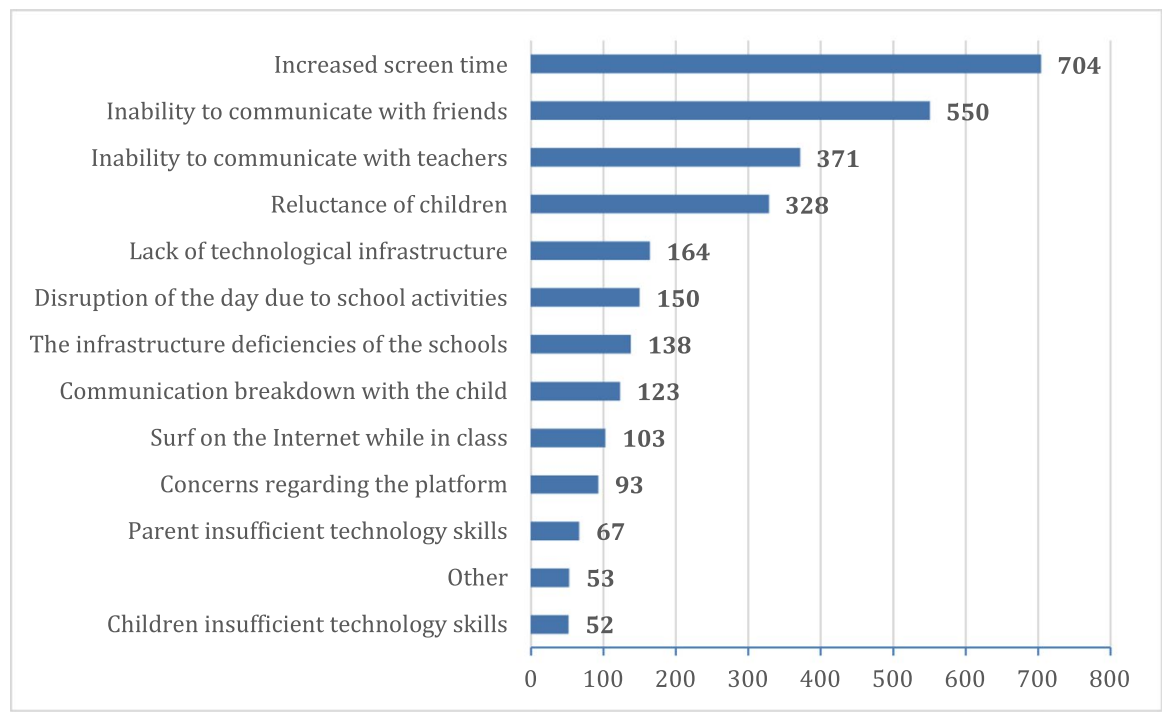

Fig. 7 Disadvantages of the remote teaching 
course durations, branch diversity, motivation issues, issues of the age/skills, and evaluation issues. Themes and sub-themes are specified in Table 2 below.

It is found that the participants whose children go to public schools ask for more live sessions. In contrast, some of the participants whose children go to private schools ask for less live sessions. This shows that public schools had less live sessions than private schools. In addition, too many live sessions exhausted the parents. Some example quotations are as follows: "The screen time definitely increased due to the very long course hours. I think the duration of the live sessions should be reduced" and "reducing the live class sessions to a more productive time instead of 40 min would be more beneficial for the students."

Lack of infrastructure (access problems to EBA, having inadequate Internet infrastructure), communication/interaction issues (lack of communication between teachers and students, lack of communication between student and student, teachers' inability to communicate with parents, on-interactive distance learning sessions), motivation issues (lack of course materials, unmotivated distance learning sessions, lack of live sessions) were found to be challenges that the participants generally mentioned. It is important that teachers stay in touch with children during this unexpected situation, not only in academic terms, but also in terms of making it easier for the students and parents to overcome this new process. Because of a lack of awareness and concerns about the remote teaching process, parents might have expected to be contacted by the school and teachers. At this point, it is very important to motivate students. Some of the parents' views on this issue are as follows. "I had trouble maintaining motivation and discipline at home" and "videos recorded by my child's own teachers were helpful for my kid to be motivated."

It is noteworthy that parents who have children with special needs and who have children in preschool stated that distance education is not suitable for this group. The

Table 2 Parents would like to change related to the remote teaching

\begin{tabular}{ll}
\hline Themes & Sub-Themes \\
\hline Infrastructure issues & - Access problems to EBA \\
& - Having inadequate Internet infrastructure \\
Communication/interaction problems & - Lack of communication between teachers and students \\
& - Lack of communication between student and student \\
& - Teachers' inability to communicate with parents \\
& - Non-interactive distance learning sessions \\
& - Long / short course durations \\
& - Increased screen time \\
& - Priority to core courses \\
Bourse durations & - Lack of consultation \\
& - Lack of course materials \\
Branch diversity & - Unmotivated distance learning sessions \\
& - Lack of live sessions \\
& - Remote teaching is unsuitable for young children \\
Issues of the age/skills & Remote teaching is unsuitable for students with special needs \\
& - Poor quality homework \\
Evaluation issues & - Poor quality exams
\end{tabular}


reason for this may be that the basic needs of these children are free to play and outdoor activities which cannot be adequately provided online. Some of the pre-school students' parents stated that "for pre-school kids, playing games is more important than education, especially during a pandemic where we have all been locked down" and "distance education could be more beneficial for children if it was not done every day for the preschool group. For this group, more interactive activities would have been prepared."

Some of the parents also emphasized the inadequacy of homework and exams in the remote teaching. One parent explained this, "I think that the exams should not have been done online, it injures the children's sense of justice." While some parents expressed their opinions about the excess of homework, a group of parents found the homework poor quality and the expectations of teachers from students insufficient. One parent explained this, "it would be much better to make attempts to encourage children to do some research related to culture, history, and handicraft rather than always asking them to complete academic related assignments." This might be caused by the way schools and teachers carry out the process.

\section{Discussion}

The study was an effort to investigate the current emergency remote teaching situation in Turkey and experiences of parents with the remote teaching during the COVID-19 pandemic. Parents' perspectives toward the remote teaching, including feelings, issues, struggles, and satisfactions they have encountered during the emergency remote teaching, and their presence during the emergency remote teaching were investigated. While little research has been conducted to understand parents' views during this kind of learning experience, parents' perspectives and experiences of the emergency remote teaching can influence the quality and quantity of online learning in the future. This study was one of the first studies about the immediate impact of the COVID-19 pandemic on education in Turkey. The study was conducted during the school year while emergency remote teaching was occurring. The study adds to the current literature by providing emergency remote teaching experiences and perspectives of a large group of parents whose children attend various grade levels in Turkey.

As an exploration of the remote teaching experience during the COVID-19 pandemic and parents' experiences and perspectives toward the remote teaching, this study has found that there are different opinions related to the remote teaching experience. The parents had different views about the remote teaching experience during this situation. This section will discuss the findings and their implications for future studies and practical improvements.

\subsection{Remote teaching practices were mainly covered in core courses}

The study found that remote teaching practices were usually covered in core courses like Mathematics, Literacy, Social Studies, and Science Education. Other courses 
like Art, Music, and Physical Education were kept in low priority. The remote education was delivered by online platform-EBA (Educational Informatics Network) and national television channel-TRT (Turkish Radio and Television Corporation). In addition to these official platforms, students and parents have used social media and the school's private learning management systems to communicate with their teachers. It is accepted that core courses such as Mathematics, Literacy, Social Studies, and Science Education are important at all grade levels. In addition to these core courses, elective courses such as Art, Music, and Physical Education would emotionally relax students and contribute to their holistic development. Especially in times of crisis, these courses would help to reduce the negative effects of a disease outbreak on the physical and mental health of children. This would include psychological impact such as longer durations of quarantine, fears infection, frustration, and boredom. For this reason, apart from the core courses it is important to give distance education lessons that will contribute to the development of students and make them feel good in this difficult situation.

\subsection{Remote teaching for young children and students with special needs}

The findings revealed that the majority of young children (pre-school and primary school level) attended online classes with a parent present. Compared to the students who are older, young children and students with special needs needed assistance in addition to technical support. The parents of these groups also found distance education not suitable for their children. A study conducted by Dong et al. (2020) also found that Chinese parents had negative beliefs and attitudes for their young children around online learning during the COVID-19 pandemic. Chinese parents also reported that "online education lacked a learning atmosphere and social interactions to engage young children, resulting in poor learning outcomes" (Dong et al., 2020). Similarly, a study conducted by Trzcińska-Król (2020) which aimed to learn about the situation of a child with special educational needs during the COVID-19 pandemic distance learning, the parents of those children found the distance learning process stressful for their children and not conducive to learning.

These negative beliefs of parents about distance education could be caused by the sudden shift to remote teaching during the COVID-19 pandemic. In a normal situation, the parents would expect an education that includes free play and outdoor activities for their young children (Erdogan et al., 2019). Parents' standards of education have been questioned because of remote teaching. Considering that there is still a concern that recreation is diminished by technology (Marsh \& Bishop, 2014), this has led parents to believe that digital technology is inappropriate for these groups (Erdogan et al., 2019). With the COVID-19 pandemic, remote teaching has become unavoidable and distance education may become an important part of our lives in the future, so to support parents and children to use technology and distance education better and to investigate the appropriate use of technology at home and in schools empirical research studies are needed. These kinds of studies and parental education would change parents' beliefs toward technology and online education. 


\subsection{Social isolation and lack of interactivity}

According to the results of the study, most parents had a concern about social isolation and lack of direct interaction with teachers and peers during the remote teaching experience. Like other studies conducted during the pandemic (Dong et al., 2020; Garbe et al., 2020), most of the parents stated that there was not enough communication between their children and teachers, and peers during the remote teaching process. While with the COVID-19 disease, social distancing has been repeatedly suggested as a preventive strategy, the lockdown has also brought social isolation and lack of interactivity. All these negative effects of COVID-19 have made parents associate these with distance learning. The emergent transformation to remote teaching has made them more resistant to distance education. However, distance education itself might not be the cause of these concerns (Dong et al., 2020). This implies that the design and delivery of distance education during crises like COVID-19 need to be well planned to decrease these negative effects. In addition, parental training sessions might be considered to better prepare the parents for distance education.

\subsection{Increased screen time}

According to the parents, the biggest challenge experienced in the process was the increase in the time spent in front of the screen. The parents considered the increased screen-time as a challenge of the remote teaching experience. This concern is understandable as screens were the children's only way to interact with their peers and teachers. In addition to the remote teaching practices, the children' screen time was increased by watching TV and using computers, tablets, and phones as they have been at home almost the whole day. The parents believed that their children spent too much time watching TV, playing online games, and using social media. Like the Dong et al. (2020) study, parents were concerned about the screen time that the children spent during the COVID-19 pandemic. This finding is also consistent with the existing literature that reported parents and educators concerns about the negative effect of screen time on children (Rhodes, 2017). In order to regulate children's screen time especially during this time, parents could set up rules for technology use at home (Nouwen \& Zaman, 2018). Moreover, this concern should be carefully considered by the educational authorities when designing online learning programs. Online learning programs that require students to sit in front of a screen for half of the day or even a whole day should be reorganized with more offline and/or physical activities by considering the children's age and interests.

\subsection{Burdensome of online learning}

The parents in this study also reported a burden brought on them by remote teaching. The parents struggled to support their children learning during remote teaching. The excessive burden of parents to support children during remote teaching also damaged their relationship with the children. Parents who have a huge role in 
running the distance learning process were emotionally worn out when they do not know enough about how the process will proceed. This has also been reported in other studies that online learning placed a heavy burden on caregivers and parents (Chang \& Satako, 2020; Dong et al., 2020; Garbe et al., 2020; Pew Research Center, 2020). In Dong et al. (2020) study, the parents even perceived online learning as time-consuming. In Chang and Satako (2020) study which was conducted with UNESCO's Section of Education Policy, it is found that countries have provided several kinds of support for parents and caregivers during the COVID-19 pandemic. For example, China provided online pedagogical support to parents, Italy provided online courses for parents on the ways to manage the relationship with their children during lockdown, Spain provided diverse communication platforms and applications that teachers and parents collaborate on the childrens learning process, Saudi Arabia used its official Twitter account to regularly spread information about online learning. It is understandable that the lockdown and remote teaching has added burden to parents and this needs to be carefully considered and well planned to support parents during emergent situations like COVID-19.

\subsection{Self-regulated learning and digital socialization}

Most parents who attended the study also expressed that the remote learning process they underwent partially contributed to their children's self-regulated learning. In contrast to the Dong et al. (2020) study, the parents in this study believed that their children's self-regulated learning skills have increased during remote teaching. This could be because of the cultural differences between Turkey and China. As Dong et al. (2020) noted in their study "the Chinese parents highly valued the linkage of self-regulation to the Confucianism heritage that children should be self-restraint and self-regulate to follow the social rules and norms" (p. 7). In contrast, Turkish parents might not have such a strict connection between self-regulation and culture. Another study exploring the students' self-regulated learning behaviors in the remote teaching during the COVID-19 pandemic should be conducted to understand how self-regulation is defined by parents.

Social isolation has been reported as a shortcoming of the emergency remote teaching in studies conducted during the pandemic, including this particular study. The study also found that digital socialization was voiced by parents as a skill their children acquired during remote teaching. Different than other studies conducted during the pandemic, digital socialization was voiced by the parents in this study. In order to survive emergency remote teaching, all stakeholders of education including teachers, parents, and students had to gain skills needed in a digital environment. Some basic skills such as using a computer (e.g., turning on/off the computer, installing an application, saving a file) and using the Internet can be considered prerequisites of attending remote teaching. All of these technical skills are also needed for the acquisition of 21 st-century digital skills (Van Laar et al., 2017). The emergency remote teaching experienced during the pandemic has accelerated digital adoption. Increased engagement with technology has become a requirement of 
students for educational purposes. The increasing use of technology for educational purposes during the pandemic has also influenced the acquisition of 21 st-century digital skills. Future researchers could go into greater depth on how the expanded use of technology by children and parents during the pandemic affected their 21 stcentury digital skills dimension.

\section{Conclusion and implications}

The coronavirus disease 2019 (COVID-19) pandemic caused an emergency transform from traditional to distance learning and it is called emergency remote teaching. The circumstances were unpredictable and unusual for teachers, students, and parents, as opposed to a well-planned online learning experience.

A well-planned online learning experience is a complex process where a careful instructional design and development is needed to create an effective learning environment. The remote teaching process that entered our lives with COVID-19 can be considered as a new platform for students, parents, teachers, and schools. For this reason, it is understandable and expected to have glitches and deficiencies in the process. One of the problems that students encountered was the communication problem caused by not being able to share the same physical environment with their peers and teachers. Thus, in such an online environment, teachers' efforts would be particularly important in terms of both staying in touch with students and supporting communication between students.

It is especially important not to perceive the distance education process as academic for the younger children (pre-school level) and to remember that the basic need of children in this period is free play and outdoor activities. For this reason, if teachers convey that they also experience similar feelings and needs, such as staying in touch with their students, missing their friends and teachers, this would help younger children to overcome the situation more easily. In a face-to-face class, communication, and interaction outside of academic circles simultaneously become a part of the teaching and learning process. However, when online classes are mainly designed to convey academic knowledge, students get easily bored. For this reason, it is important to carefully plan online learning experiences so that the students spend efficient time during online lessons. This can be done by orienting students to be active outside of the live sessions, with interesting questions and various project assignments. Teaching in this way will not only attract the attention of children, but also motivate students to take responsibility of their learning and thus knowledge construction.

The emergency remote teaching that entered our lives with the COVID-19 pandemic provided an understanding of the role of the school outside of education. It has shown that the school is not only a place of learning, but also a social common space that provides socialization, care, facilitation, and coaching. In addition, it has also revealed that technology is inevitable and distance education may become an important part of our lives in the future. 


\section{References}

Abdulamir, A. S., \& Hafidh, R. R. (2020). The possible immunological pathways for the variable immunopathogenesis of COVID_19 infections among healthy adults, elderly and children. Electronic Journal of General Medicine, 17(4), em202. https://doi.org/10.29333/ejgm/7850.

Beckman, K., Bennett, S., \& Lockyer, L. (2019). Reproduction and transformation of students' technology practice: The tale of two distinctive secondary student cases. British Journal of Educational Technology, 50(6), 3315-3328. https://doi.org/10.1111/bjet.12736.

Berg, B. (2009). Qualitative research methods for the social sciences. . Allyn \& Bacon.

Bozkurt, A., \& Sharma, R. C. (2020). Emergency remote teaching in a time of global crisis due to CoronaVirus pandemic. Asian Journal of Distance Education, 15(1), i-vi. https://doi.org/10.5281/zenodo.37780 83.

Brazendale, K., Beets, M. W., Weaver, R. G., Pate, R. R., Turner-McGrievy, G. M.,\&nbsp;Kaczynski, A. T., ..., \& von Hippel, P. T. (2017). Understanding differences between summer vs. school obesogenic behaviors of children: The structured days hypothesis. International Journal of Behavioral Nutrition and Physical Activity, 14(100), 1-14. https://doi.org/10.1186/s12966-017-0555-2.

Brooks, S. K., Webster, R. K., Smith, L. E., Woodland, L., Wessely, S., Greenberg, N., \& Rubin, G. J. (2020). The psychological impact of quarantine and how to reduce it: Rapid review of the evidence. The Lancet, 395(10227), 912-920. https://doi.org/10.1016/S0140-6736(20)30460-8.

Chang, G.C., \& Satako, Y. (2020). How are countries addressing the Covid-19 challenges in education? A snapshot of policy measures. World Education Blog. https://www.gecv.ac.in/uploads/ssip/UNESCO\% 20snap\%20shot\%20for\%20maintaining\%20education.pdf.

Dong, C., Cao, S., \& Li, H. (2020). Young children's online learning during COVID-19 pandemic: Chinese parents' beliefs and attitudes. Children and Youth Services Review, 118, 105440. https://doi.org/ 10.1016/j.childyouth.2020.105440.

Erdogan, N. I., Johnson, J. E., Dong, P. I., \& Qiu, Z. (2019). Do parents prefer digital play? Examination of parental preferences and beliefs in four nations. Early Childhood Education Journal, 47(2), 131-142. https://doi.org/10.1007/s10643-018-0901-2.

Ergulec, F. (2019). Instructional strategies for forming online collaborative teams. International Journal on E-Learning, 18(4), 349-372. https://www.learntechlib.org/primary/p/207505/.

European Centre for Disease Prevention and Control (2020). Outbreak of novel coronavirus disease 2019 (COVID-19): Increased transmission globally - fifth update. European Centre for Disease Prevention and Control. https://www.ecdc.europa.eu/sites/default/files/documents/RRA-outbreak-novel-coronavirus-disease-2019-increase-transmission-globally-COVID-19.pdf.

Feng, L., \& Cavanaugh, C. (2011). Success in online high school biology: Factors influencing student academic performance. The Quarterly Review of Distance Education, 12(1), 37-54,71-72. https://search. proquest.com/scholarly-journals/success-online-high-school-biology-factors/docview/920291750/se-2? accountid $=16716$.

Garbe, A., Ogurlu, U., Logan, N., \& Cook, P. (2020). Parents' experiences with remote education during COVID-19 school closures. American Journal of Qualitative Research, 4(3), 45-65. https://doi.org/10. 29333/ajqr/8471.

Hodges, C., Moore, S., Lockee, B., Trust, T., \& Bond, A. (2020). The difference between emergency remote teaching and online learning. Educause Review, 27, 1-12. https://er.educause.edu/articles/2020/3/thedifference-between-emergency-remote-teaching-and-online-learning.

Hollingworth, S., Mansaray, A., Allen, K., \& Rose, A. (2011). Parents' perspectives on technology and children's learning in the home: Social class and the role of the habitus. Journal of Computer Assisted Learning, 27, 347-360. https://doi.org/10.1111/j.1365-2729.2011.00431.

Lase, D., Zaluchu, S. E., Daeli, D. O., \& Ndraha, A. (2020). Parents' perceptions of distance learning during Covid-19 pandemic in rural Indonesia. https://doi.org/10.35542/osf.io/hfza7.

Lee, M., \& Figueroa, R. (2012). Internal and external indicators of virtual learning success a guide to success in K-12 virtual learning. Distance Learning, 9(1), 21-28.

Lincoln, Y. S., \& Guba, E. G. (1985). Naturalistic inquiry. Sage Publications.

Liu, F., Black, E., Algina, J., Cavanaugh, C., \& Dawson, K. (2010). The validation of one parental involvement measurement in virtual schooling. Journal of Interactive Online Learning, 9(2), 105-132. https:// www.ncolr.org/jiol/issues/pdf/9.2.2.pdf.

Marsh, J., \& Bishop, J. C. (2014). Changing play: Play, media and commercial culture from the 1950s to the present day. Open University Press/McGrawHill. 
Nouwen, M., \& Zaman, B. (2018). Redefining the role of parents in young children's online interactions. A value-sensitive design case study. International Journal of Child-Computer Interaction, 18, 22-26. https://doi.org/10.1016/j.ijcci.2018.06.001.

Palloff, R. M., \& Pratt, K. (2013). Lessons from the virtual classroom (2nd ed). Jossey-Bass.

Parczewska, T. (2020). Difficult situations and ways of coping with them in the experiences of parents homeschooling their children during the COVID-19 pandemic in Poland. Education, 3-13, 1-12. https://doi. org/10.1080/03004279.2020.1812689.

Pew Research Center (2020). COVID-19: Effect on personal life. Pew Research Center. Retrieved October 15, 2020, https://www.pewresearch.org/pathways-2020/cvchildcare/total_us_adults/us_adults/.

Rhodes, A. (2017). Screen time and kids: What's happening in our homes. Detailed report. Melbourne (VIC): The Royal Children's Hospital Melbourne. http://www.rchpoll.org.au/wp-content/uploads/2017/ 06/ACHP-Poll7_Detailed-Report-June21.pdf.

Povey, J., Campbell, A. K., Willis, L.-D., Haynes, M., Western, M., Bennett, S., Antrobus, E., \& Pedde, C. (2016). Engaging parents in schools and building parent-school partnerships: The role of school and parent organization leadership. International Journal of Educational Research, 79, 128-141. https:// doi.org/10.1016/j.Ijer.2016.07.005.

Şimşek, H., \& Yıldırım, A. (2011). Sosyal bilimlerde nitel araştırma yöntemleri [Qualitative research methods in the social sciences]. Seçkin Yayıncılık.

Telli Yamamoto, G., \& Altun, D. (2020). Coronavirüs ve çevrimiçi (online) eğitimin önlenemeyen yükselişi [The coronavirus and the rising of online education]. ÜniversiteAraştırmalarıDergisi, 3(1), 25-34. https://doi.org/10.32329/uad.711110.

Trzcińska-Król, M. (2020). Students with special educational needs in distance learning during the COVID19 pandemic-parents' opinions. Interdisciplinary Context of Special Pedagogy, 29(1), 173-191. https:// doi.org/10.14746/ikps.2020.29.08.

UNESCO (2020). COVID-19 education response. UNESCO. Retrieved October 15, 2020, https://en.unesco. org/covid19/educationresponse.

UNICEF (2020). UNICEF and Microsoft launch global learning platform to help address COVID-19 education crisis. UNICEF. Retrieved October 15, 2020, https://www.unicef.org/ukraine/en/press-releases/ unicef-and-microsoft-launch-global-learning-platform-help-address-covid-19-education.

Van Laar, E., Van Deursen, A. J., Van Dijk, J. A., \& De Haan, J. (2017). The relation between 21st-century skills and digital skills: A systematic literature review. Computers in Human Behavior, 72, 577-588. https://doi.org/10.1016/j.chb.2017.03.010.

Vygotsky, L. S. (1978). Mind in society. M. Cole, V. John-Steiner, S. Scribner, \& E. Souberman (Eds.) Mind in Society the Development of Higher Psychological Processes (p. 159). Harvard University Press.

Wang, G., Zhang, Y., Zhao, J., Zhang, J., \& Jiang, F. (2020). Mitigate the effects of home confinement on children during the COVID-19 outbreak. The Lancet, 395(10228), 945-947. https://doi.org/10.1016/ S0140-6736(20)30547-X.

Yin, R. K. (2009). Case study research: Design and methods (4th ed.). Sage Publications.

Publisher's note Springer Nature remains neutral with regard to jurisdictional claims in published maps and institutional affiliations. 